\title{
Stability estimation of slopes having their slip surface determined by means of the STAB-3D method based on sliding body equilibrium analysis
}

\author{
Janusz UKLEJA* \\ 1 Opole University of Technology, Faculty of Civil Engineering and Architecture, Katowicka 48, 45-061 Opole, Poland
}

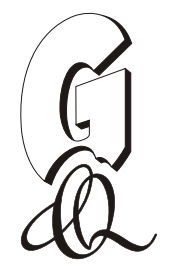

\begin{abstract}
Ukleja, J., 2016. Stability estimation of slopes having their slip surface determined by means of the STAB-3D method based on sliding body equilibrium analysis. Geological Quarterly, 60 (3): 597-609, doi: 10.7306/gq.1276

Most of the three-dimensional analyses of landslides are based on simple 2D methods analysing chosen characteristic flat sections of the analysed sliding body. Assumptions of the method of flat limit equilibrium analysis for a spatial solution have been elaborated. This is a combination of 2D analysis of flat sectional views and 3D analysis of the landslide's sliding body, which disregards any stress that does not affect equilibrium. It is assumed, however, to apply only when dealing with structural slope failure (i.e. when the soil layers have the predisposition to shape the determined slip surface with a consistent decrease and explicit slide direction). This can also apply when examining the stability of a scarp or slope for the layered soil of potential slip surfaces and slide direction to be defined. The basic assumptions, equilibrium equations, and practical usage of the method have been described for an exemplary landslide. This method allows one to define in a straightforward manner the stability of slopes, to plan a way of preventing potential landslides, and to control those that have already arisen.
\end{abstract}

Key words: slope stability, three-dimensional analysis, layered soils, safety, landslides.

\section{INTRODUCTION}

For a long time, efforts have been made to perfect known methods and to develop new methods by means of three-dimensional (3D) block analysis, especially in order to create the basis of 3D analysis. Results obtained so far are limited to a great extent, being sometimes subject to many modifications; in some cases there are no satisfying results. For over 30 years, many workers have dealt with this subject matter, for example Chen and Chemeau (1983), Hutchinson and Sarma (1985), Hungr (1987), Zhang (1988), Michalowski (1989), Huang and Tsai (2000), Huang et al. (2002), Cheng et al. (2005), Griffiths and Marquez (2007), Wei et al. (2009) and Kalatehjari et al. (2015), who tried to consider the 3D profile of slope stability analysis.

Apart from the known and long-used flat methods of slope analysis, there is also a group of numerical methods, including computer programs, stemming from the solution based on the mechanics of the continuous medium theory, used for fragmented formations such as soil. The numerical programs analyse the soil based on the assumptions of the following methods: finite-difference, finite-element, and boundary element. Most may serve the purpose of both defining the load causing the stability loss, as well as checking the stability of a scarp or slope. The most widespread numerical method is the algorithm of shear strength reduction (SSR). This technique consists of gradually

*E-mail: ukleja2012@gmail.com

Received: July 29, 2015; accepted: February 8, 2016; first published online: February 8, 2016 reducing the shear strength and observing the behaviour of the slope until it loses stability, i.e. until the established, initial safety factor has the value $F S=1$. The second modified shear strength reduction method (MSSR) is a modification of the SSR method and, given more complicated slope shape and differentiated soil layers, allows the determination of potential routes of stability loss lines (slide), contrary to the SSR method of only a single line. Many 3D analytical methods based on numerical methods have been presented by, for example, Hicks and Spencer (2010) and Li et al. (2010) with reference to slopes of an elongated shape and by Nian et al. (2012) and Zhang et al. (2013) with reference to slopes with the effect of turning a corner.

There are also other methods addressing the stability of scarps, which describe stability problems in other ways than numerical methods, obtaining results that reflect the real movement of the slopes. One such method is described by Vandamme et al. (2012), which is a novel particle method for modelling the episodic collapse of soft coastal bluffs, based on the bluff morphology model (BMM). This method, supported by comparison with the discrete elements method and the results of the model research (Vandamme and Zou, 2013), allows the stability issue to be studied more profoundly and also describes the process of creating and developing the landslide on seaside slopes. Issues related to the influence of subterranean water, especially hydrostatic and hydrodynamic pressure, are also described in Zhang et al. (2005). The influence of these factors on initiating landslide processes next to forced vibrations is often underappreciated in analysing the stability of slopes.

However, Cheng and Yip (2007) included a new approach to $3 \mathrm{D}$ analysis of slope stability, broadening the possibilities of the already known and used 2D methods: those of Bishop, Janbu and Morgenstern-Price. They formulated the stability as- 
sumptions in a 3D space, with regard to major slide inclination of ground masses and to the cross direction. Such analysis is recommended for use in more complex conditions of layer construction. Therefore, it is possible to use known and checked 2D methods, on flat sections, for the 3D analysis in the space of the whole block. Similar conclusions result from Loehr et al. (2004). They described a quasi-3D method based on conventional $2 \mathrm{D}$ analysis of the slope's stability, specified as the resistance-weighted (RW) procedure. It is an approximate method and increases the value of the safety factor by around $10 \%$ compared to other 3D methods. Michalowski (2010), as a result of research conducted on the kinematic basis of the limit analysis, formulated conclusions defining the relationship of the slope's safety factors comparing 2D and 3D approaches. Examining the $3 \mathrm{D}$ shape of the rotational failure pattern of slopes, it was proved that, for different proportions of dimensions and external loads applied to slopes in the 2D method, analysis of the same slides leads to safety coefficients lower than those in the case of the 3D method. The differences, depending on the ratio of the width to the height of the block, may reach up to $50 \%$ (at the ratio of $1: 1$ ) and $10 \%$ (at the ratio of $5: 1$ ).

McCombie (2009) dealt with developing the method of Sarma-Hoek, which is widely used today. This method has been extended by calculation modification with regard to the deformations caused by dislocations existing on the surface of the dividing line. He noticed a type of inconsistency and suggested using iteration, to define the equilibrium of forces and moments acting and counteracting, in the form of resistance forces, which reduces the resulting deformation of the results. This indicates an imperfect profile of the assumed division into basic elements of sides that are not vertical and not parallel to each other

Zhu (2001) described the method of locating the critical slip surface of any shape while analysing the slope stability. Based on the optimisation rule, the critical slip surface was found. The procedure has been developed to identify the critical slip surface for all possible slip surfaces. The surface for which a safety factor is the lowest is defined in terms of the critical slip surface. This method may be useful for all kinds of equilibrium limit methods, whereas Zamani (2008) examined the problem of rocky slope stability, using 3D analysis, for which the sliding surface of the block is determined with regard to the profile of the rock formations. A similar analysis method may be used for more complex rocky-ground formations, for example, flysch. According to this research, the aim is to specify 3D block stability and to define all potential slip surfaces in order to choose the most unfavourable.

The aforementioned analysis models provide for assessment of the stability of landslides sliding body (LSB), which - to a lesser or greater extent - correspond to failure mechanisms. They mainly account for the analysis of LSB, as a type of continuum characteristic of fixed strength parameters. The stability of this sliding body should not be affected if a target safety factor and land surface parameters have been ensured. Nevertheless, analyses and observations indicate that some failures prove variable velocity (ranging from slow movements to periodical stability, and even sudden quick movements). This variable velocity is caused by a number of factors such as pressure, seismic effects, and water lift that affects modification of strength parameters. During the landslide, the sliding body normally shows disturbed stability that causes deconsolidation or even decomposition inside the LSB. Therefore, the approach based for instance on numerical methods derived from the theory of continuum mechanics seems to be inadequate for active slope failures. On the other hand, the approach based on assessment static stability determined in the blocks by balance of forces may reliably provide an accurate global stability assess- ment of LSB. However, it is of the utmost importance to take into account all and any key factors that may influence out-of-balance forces. The majority of applicable assessment models do not address all the factors that may have a significant impact upon slope stability, since those are simplified or limited numerical models. The factors particularly refer to the following:

- the option to distinguish three-dimensional zones in LSB, which stabilise it, and other zones that may cause displacements in the whole sliding body by out-of-balance forces;

- the forces originating from hydrostatic and hydrodynamic pressure of subterranean water in every single piece of the sliding body that depends on the variable level of subterranean water;

- the stresses caused by vehicles as well as machinery and equipment, and seismic movements;

- the impact of support structures or stability support facilities such as reinforced concrete, injection or anchoring of the landslide body in the stable mass formation.

All these aspects are extremely significant especially for practical applications. It is not only in the case with slope failure risk, but for engineering mitigation measures in the case of active failure by landslides. In view of available slope stability assessment approaches and the need to address these factors, a simple quasi three-dimensional approach has been developed and effectively applied under the abbreviated name of STAB-3D (derived from the words: stability and three dimensions). This approach and related assumptions are described below. The accuracy of this approach has been challenged in practice, as it has been applied to active slope failures in southern Poland. This approach is based on widely known and acceptable rules of soil mechanics and rules of stability; therefore, all the aforementioned stability and strength factors can be addressed in a simple and transparent manner. It has proven to be successful and efficient in practical application, remedying several active slope failures. This especially refers to the cases of the necessity to remedy active and slowly moving slope failures that are in a state of vulnerable stability, or periodically become active slope failures.

This method of three-dimensional analysis of slope stability STAB-3D constitutes a new approach to the issue of 3D landslide sliding body stability, in relation to structural slope failure. It applies only to the slope failure on a determined sliding surface (i.e. when the soil layers shape the determined slip surface with a consistent decrease and explicit slide direction). This method includes all the main factors existing in nature and significantly influencing the stability of the analysed sliding body. These include factors such as the hydrostatic and hydrodynamic pressure of the subterranean water, external loads, supporting forces caused by the use of supporting devices and anchor plates, and the possibility of including forces caused by influencing forced vibrations, for example vehicles. It is possible to define a stability factor for both scarps and stable slopes, showing the symptoms of losing stability and active landslides. The method may also be used to predict the range of potential landslides in stable areas of the rock mass.

\section{DESCRIPTION OF THE STAB-3D METHOD}

\section{ASSUMPTIONS}

Based on the plane static equilibrium system of the slope section, an analysis method for the spatial system of the sliding body of structural landslides has been developed. As a result of 
this analysis, it has become possible to determine the dimensions of potential landslides (structural slope failure) of endangered sections of slopes and to determine the stability of the whole sliding body in the soil, as well as the dimensions of potential landslides in predestined forms, for example a gutter. It was assumed that, in the block equilibrium analysis of sliding body of the landslide, the following factors are taken into consideration: any potential loads coming from the soil's own weight and external influences (e.g., uplift pressure, the hydrostatic and hydraulic pressures of water, loads of motor vehicles and trains, dynamic and seismic vibrations and devices preventing landslides, such as buttresses, anchor plates, supporting structure) in the form of forces to the specific separate elements of which it consists.

The STAB-3D method is a type of limit equilibrium method (LEM) dealing only with landslides of a structural type slope failure given the determined sliding surface, making it possible to calculate the safety factor (also known as factor of safety) $F S$ for the ensuing spatial landslides, in a situation where:

- the range and thickness of a landslide are determined by the geological-engineering conditions of the soil and by loads; then, one dimension of the factor of safety FS is pursued;

- there may be some hypothetical established slip surfaces (slide) and the most advantageous factor of safety $F S_{\min }$ should be defined (Ukleja, 1996);

- geological-engineering conditions of the soil and the loads of the slopes are very complicated: on a part of the slope, the landslide processes are ongoing and determining the range of their development and their condition, for the safe use of the area neighbouring the landslides, is required (Ukleja et al., 1999);

- the resulting structural landslide of the determined sliding surface requires stability and corrective actions to be planned with the use of anchor plates, buttresses and supporting structures and, when necessary, the influence of the actions on the stability of the whole LSB must be found by determining the change in the factor of safety FS (Ukleja and Ukleja, 1999).

The gutter shape of the LSB causes sliding forces to arise in two directions: along the syncline of the gutter and perpendicular to it (Ukleja, 1996). For the purpose of stability analysis, the LSB equilibrium conditions were determined in the direction of the consequent axial tilt of the sliding body. The conditions are expressed by the factor of safety $F S_{b}$, being the relation (i.e. quotient) of the supporting forces to the sliding forces in the area of the analysed LSB.

These assumptions do not relate to the landslide of a cylindrical slip surface (circular in cross-section), which can arise for example in homogeneous non-cohesive soils. The method applies only to cases where, at the border between layers of soil, a sliding layer was unequivocally formed. It is the "weakest link" of balance, which gives shape to a landslide sliding body. This is mainly the solid equilibrium condition to displacement on such a layer, and one of the underlying assumptions of the method. For this reason the analysis of the balance of moments was omitted.

The examined block is divided into spatial elements (Figs. 1-3) assuming that:

- between being part of LSB particular block spatial elements (Block Element 3-Dimensional [BED], Fig. 1) there is a significant force $Z_{k}$ - the resultant component of sliding force, $W_{k}$-influencing the analysed element in the cross direction to the syncline axis of the BED and the force $H_{k}$ - the component of weight $G_{i}$ (it is also the component of the force $W_{k}$ ) - sliding element in the di-
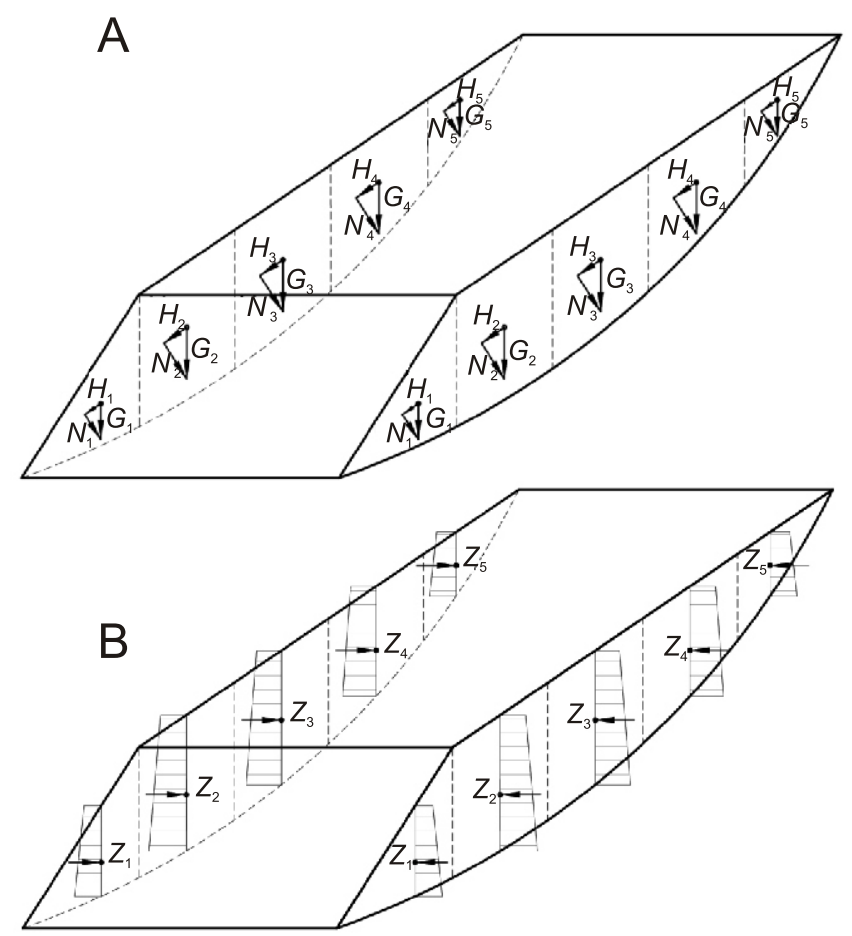

Fig. 1. Forces in cross-sections between BED elements; $(A)$ lying on slide surface of BED; $(B)$ perpendicular to slide surface of BED
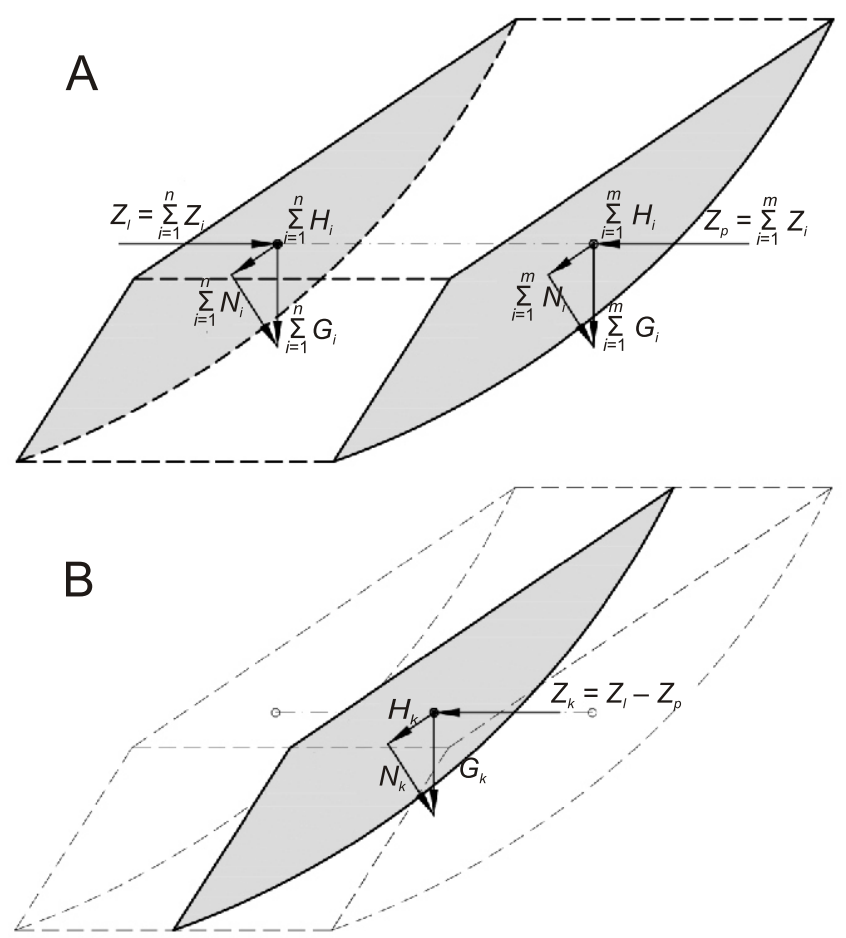

Fig. 2. A model of single block (three-dimensional element BED) after division of sliding body: (A) resultant forces for sections $B F E ;(B)$ resultant forces for the whole BED 


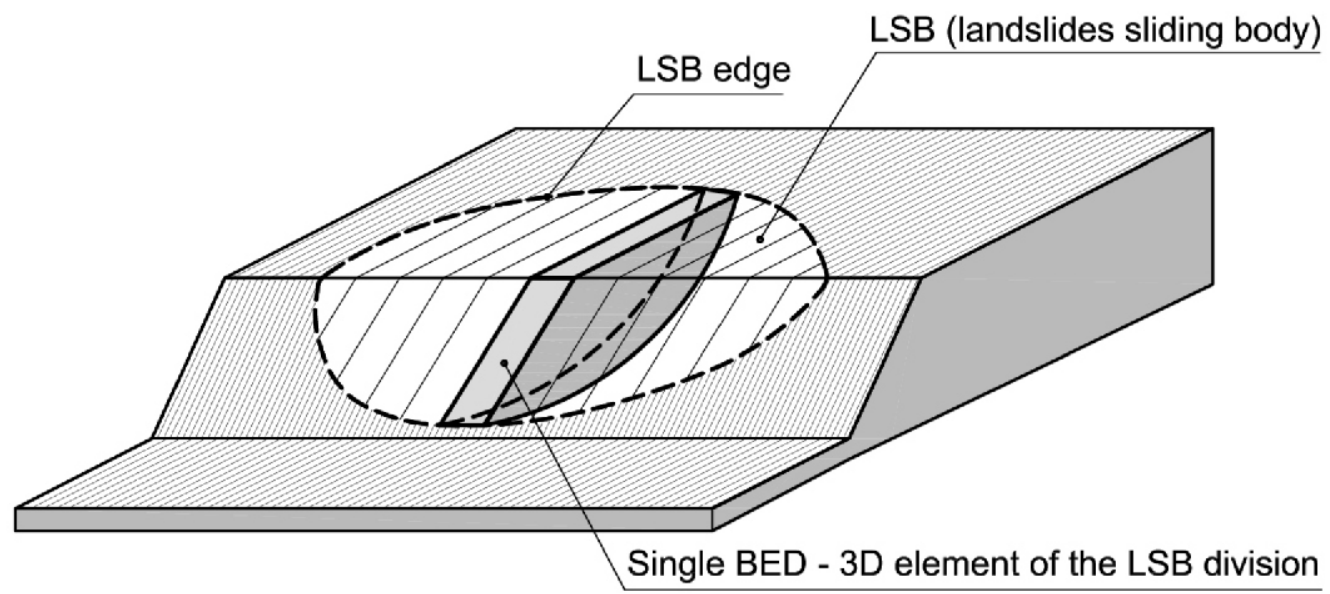

Fig. 3. The perspective view of the sliding body with division into elements BED

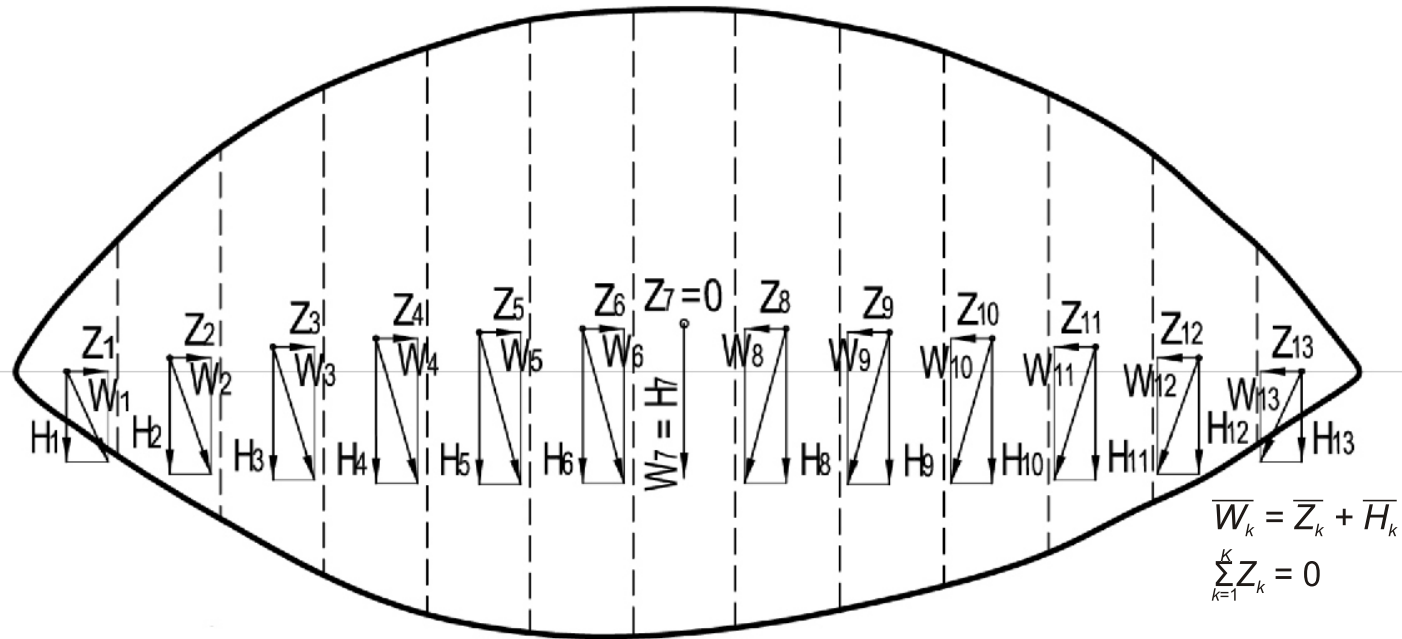

Fig. 4. The view from the top of the sliding body - internal forces in the BED elements

$$
W_{k}-\text { resultant sliding forces }
$$

rection of the contact surface slope of the landslide (Figs. 3 and 4).

- among BED elements, forces $Z_{i}$ (equally distributed on side surfaces of the BED) cause the involvement of the neighbouring BED in the cooperation of the cross and elongated directions of the axis of the landslide (Figs. 2 and 3). The forces from the equalising ground pressure between two neighbouring elements are caused by friction forces changing from a maximum dimension in the axis of the gutter, to a minimum on the edges of the LSB.
They cause its stability in the cross direction to the axis of the landslide and integrate the sliding body during its dislocation along the axis of the landslide.

- $Z_{k}$ forces equalise inside the analysed sliding body $\left(\sum_{k=1}^{K} Z_{k}=0\right)$ integrating it the most intensively into the axis of the gutter, with a decreasing tendency towards its edges, along which they are equal to 0 . 
Forces $Z_{k}$ (Fig. 4) and the cohesion $c$ between partial elements of the block BED, as mutually equalising inside the sliding body, have not been disregarded.

On the other hand, forces $H$ constitute dimensions characteristic of the forces sliding the LSB along the sliding surface. Therefore, it is assumed that each LSB constitutes the formation showing the continuum.

The assumption has three technical aspects:

a. The elements BED of the three-dimensional block are treated as the undeformable medium integrated in the area of the landslide body of special strength parameters on the sliding surface, reflecting its equilibrium conditions well, including the stratigraphy and lithology of the soil layers,

b. The accepted assumptions are closer to real conditions than those in the 2D methods used so far. This is because the stability of the whole LSB is subject to the analysis, as the group of intellectually separated BED elements, created by dividing the sliding body by sections running along the axis of the gutter (in the direction of the fall of their hill constituting the sliding surface),

c. Taking zero shear strains at the edge of the LSB at the depth $H_{c}$ (Fig. 5) causes the calculated factor of safety for the whole LSB to include, in the cohesive soil, possible contraction cracks caused by soil drying.

An interesting new method for 3D and asymmetrical slope stability analysis was presented by Huang and Tsai (2000). It was based on assumptions provided by Hungr (1987), and followed by Hungr et al. (1989). Developed and supplemented by Huang et al. (2002), it provides a basis for spatial analysis of sliding bodies of landslides. It analyses two directions: parallel and perpendicular to the assumed displacement. In addition to the classic balance of forces and moments in 3D conditions this method allows for verification of the established direction of displacement of the landslide sliding body. The STAB-3D method was adopted with similar assumptions. However, because of limitations of this method to the landslide sliding body with unequivocal direction displacement (e.g., for landslides that take place or are anticipated on the slopes of the geological structure, making an exact determination of the direction of displacement possible), it was possible to simplify this complex task. The simplification is based on cancellation of the division into 3D columns, with limitation of the analysis of the whole landslide sliding body to sections parallel to the direction of displacement. The basis for such an assumption is the fact that in a direction perpendicular to sliding, in the whole sliding body, the components of resultant forces for BED are balanced (Fig. 4). This confirms the observation of landslides that have

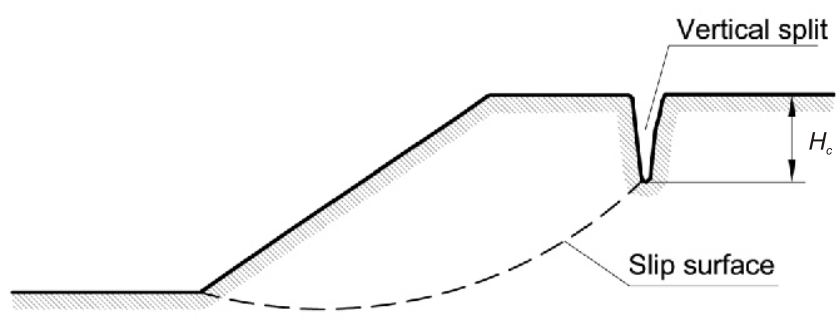

Fig. 5. The split arising as a result of stretching caused by contraction in cohesive soil only one direction of displacement, and are stable in a perpendicular direction.

In the case of cohesive soil, the height of the vertical slope, which, according to Wilun (1982), is taken as the depth of possible splits, is expressed as:

$$
H_{c}=\frac{2 \times c}{\gamma} \times \operatorname{tg}\left(45^{\circ}+\frac{\phi}{2}\right)
$$

DETERMINING THE INITIAL PARAMETERS OF A LANDSLIDE AND ANALYTICAL SOLUTIONS ACCORDING TO THE STAB-3D METHOD

When dealing with a scarp or a slope, on which a landslide may occur or a long-term landslide has already been developing, it should be recognized in a geotechnical and engineering way using all external observations (viz. cracks, land surface deformations, tilt of trees, water outflow etc.). It should be based on drilling and possibly recognizing the arrangement of layers on the slopes and the determination of a potential area of the expected landslide requiring static analysis. At this stage, it is helpful to use the measurement method of the geographic information system (GIS), described with regard to its usefulness for this type of research by Xie et al. (2006) and Shen et al. (2012).

A contour plan of a slope and the sliding plane has been created (Fig. 6). The important element of preparatory recognition is to determine the conditions of surface water flow and the influence of subterranean water in the soil wedge and in the subsoil. It is important with a view to the possibility of including the uplift pressure and the hydrodynamic and hydrostatic water pressure (which can also be described in the form of the contour plan). The geometric parameters of the slope or scarp are determined, and then are cut by sections distributed at equal distance over the whole area of the potential landslide, parallel to the direction of the contact layer fall (Fig. 6 sections A-A $\mathrm{U}-\mathrm{U})$. Based on such prepared geometric parameters, the sections are made by imposing on them the shape of a scarp or slope, the slide line, the line of the subterranean water level and the location of endangered objects or other usable loads of a slope (Fig. 7). This constitutes the initial material for analysing scarp stability (slope) using the STAB-3D method. An example of preparing the initial materials for the STAB-3D method is presented in Figures 6 and 7.

After preparing the counter plan of the privileged sliding surface in Figures 6 and 7 (Ukleja, 1996) the factor of safety $F S_{b}$ for an LSB of a 3D profile can be calculated.

\section{BASIC RELATIONS OF THE STAB-3D METHOD}

In earlier calculations for the example from Figure 6 (Ukleja et al., 1999), the equilibrium of all the sections among A-A-U-U (Fig. 7) is analysed as a flat system for particular blocks limited by the next surface of the hypothetical edge of the detachment HED I-VII. The landslide block is divided into basic flat elements (BFE: "thin stripes" of a thickness of $1.0 \mathrm{~m}$ ) in conformity with the procedure recommended by Cytowicz (1958), shown in Figures 8 and 9, for which static quantities are determined according to Equations [2]-[10] and then the factor of safety $F S_{p}$ is calculated according to Equation [11]. The collective factor of safety $F S_{b}$ is calculated from the dependences [14] for the whole analysed LSB, including all block elements (BED) shown in Figure 10 as an example. The algorithm calculation time of this procedure is small. However preparation of input data needs more work: up few to dozen hours. It depends on dividing the landslide sliding body into the BFE, and the geological layer shape. 


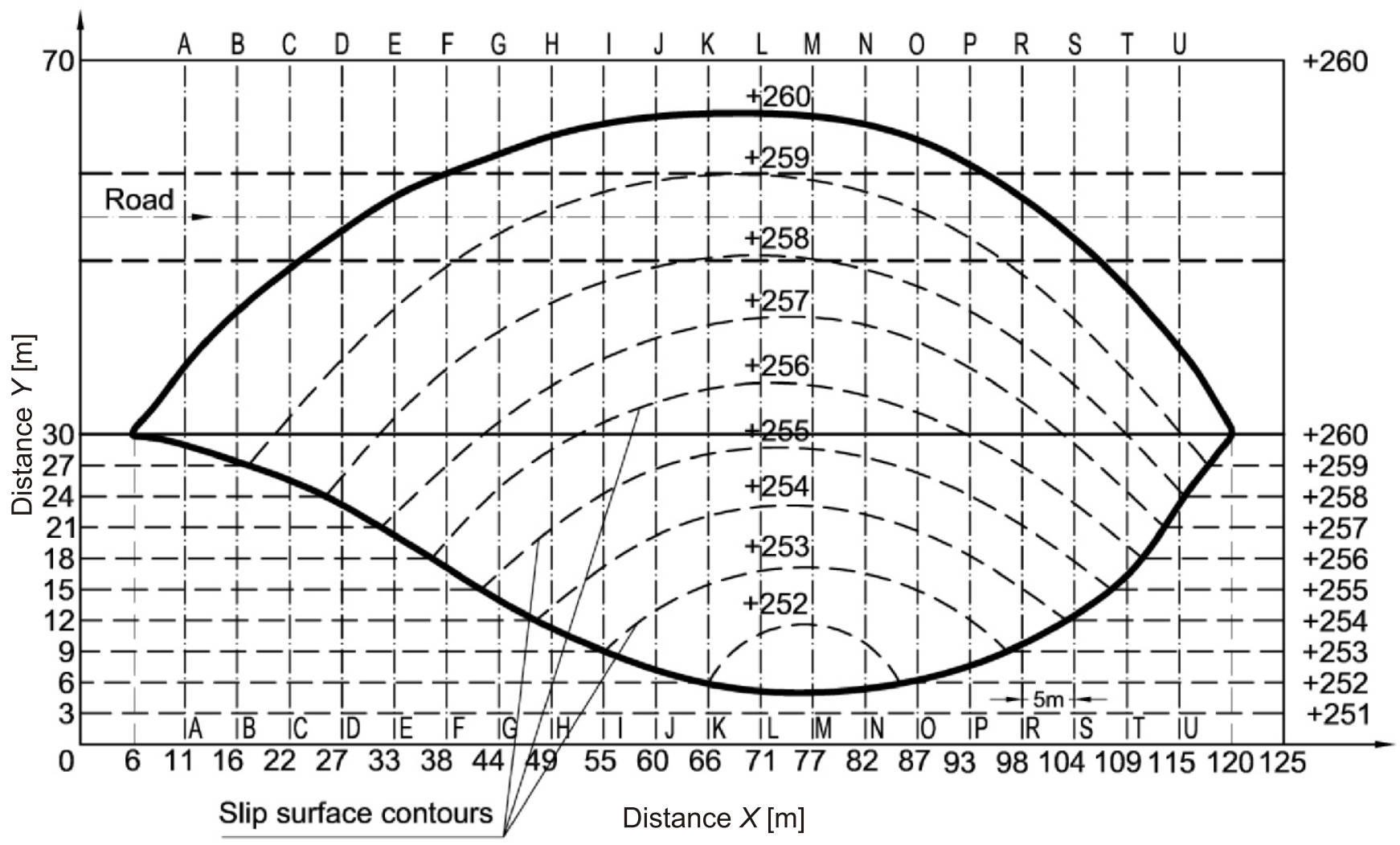

Fig. 6. The view from the top of the slope with the layered plan of the privileged sliding surface
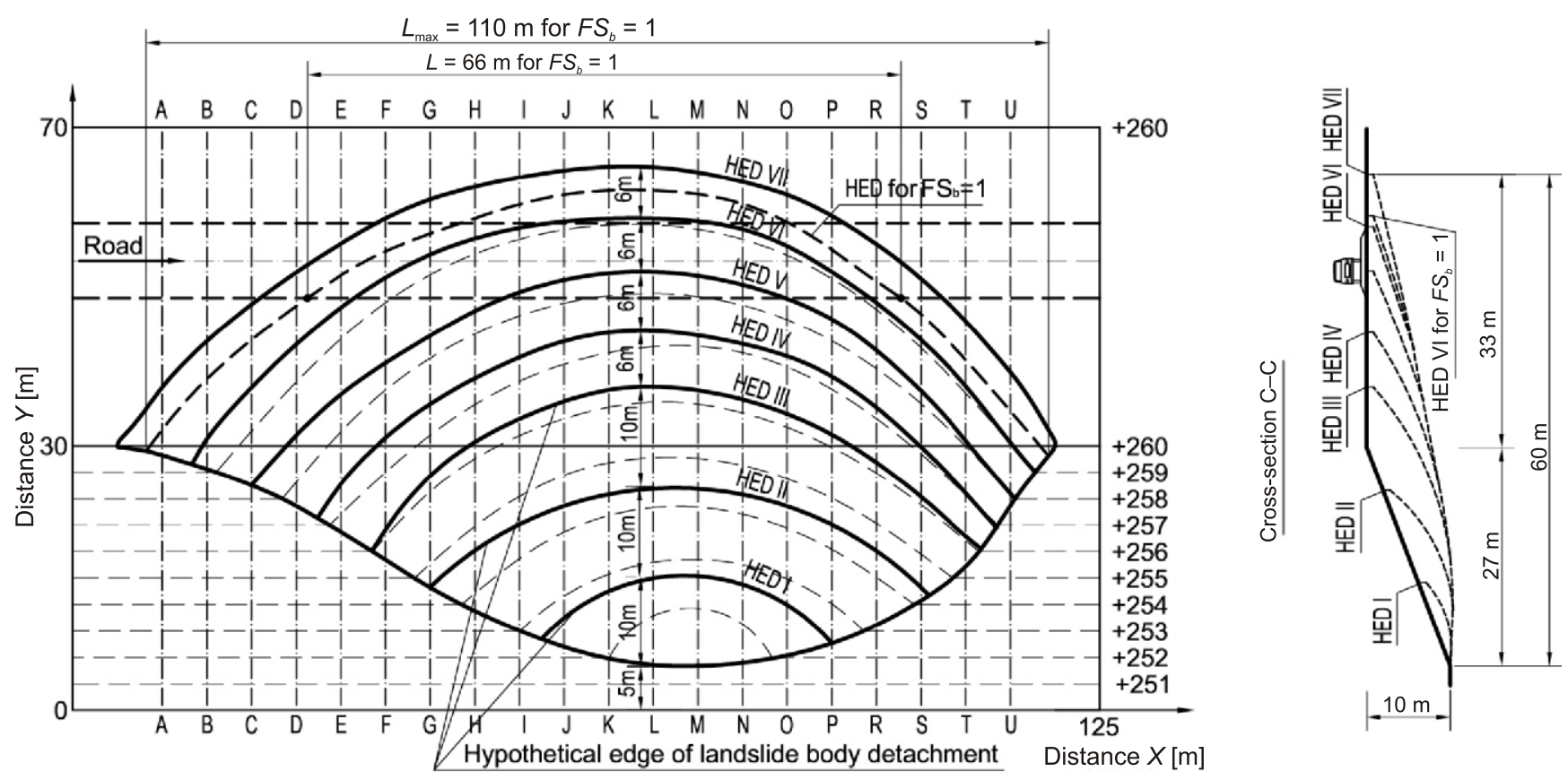

Fig. 7. The view from the top and the cross-section of the slope from the hypothetical edge of the detachment (HED) 


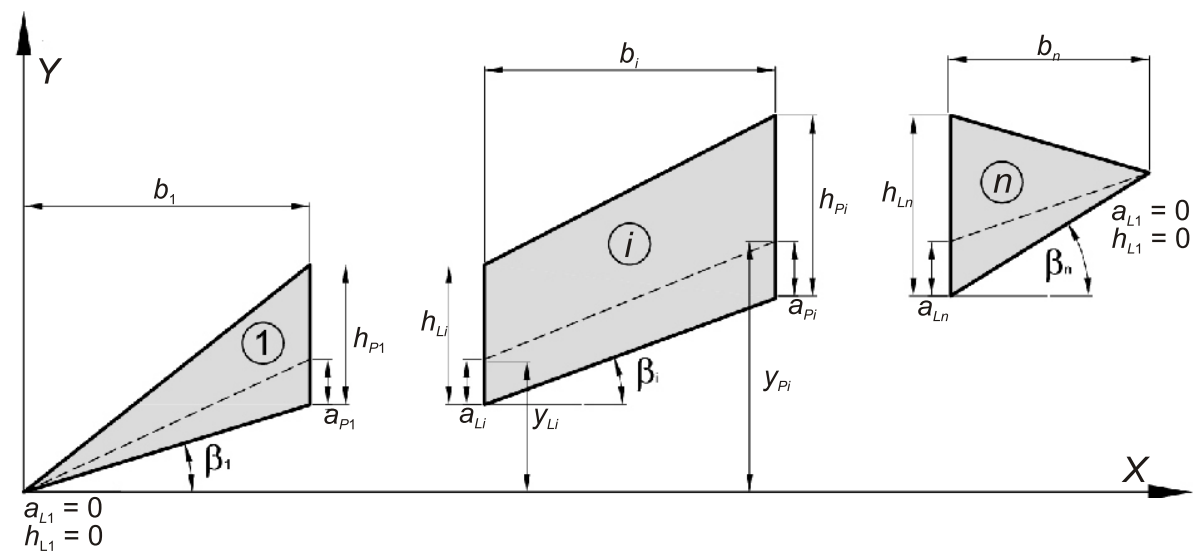

Fig. 8. The division into basic flat elements BFE for a single section through the landslide sliding body
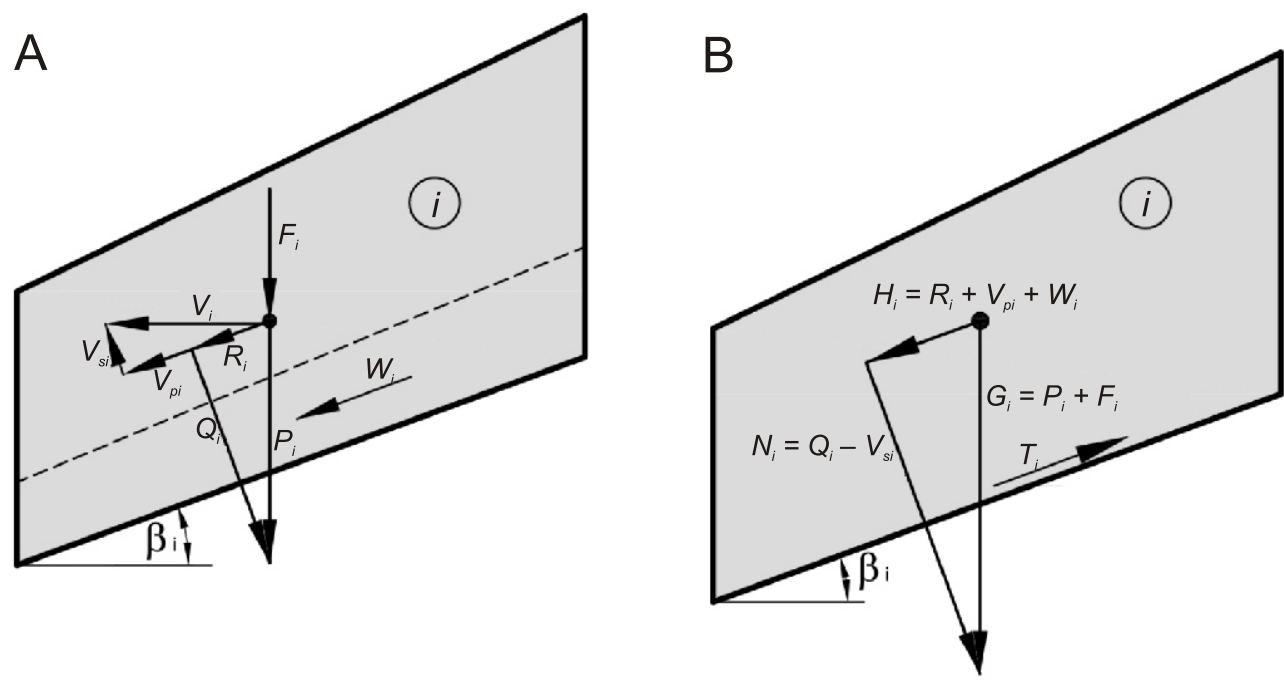

Fig. 9. Symbols and assumptions for calculating the slope safety factor for generalized, basic flat element (BFE)

A - forces in single BFE; B - resultants of forces gathered for such a single BFE

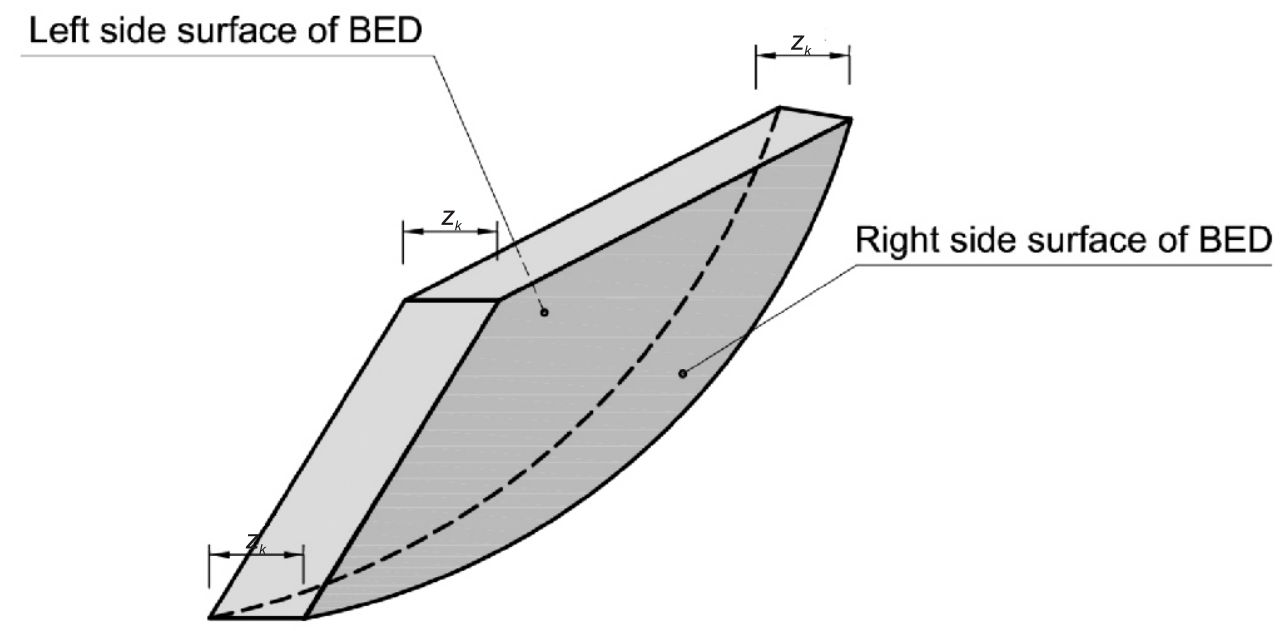

Fig. 10. Single basic BED of the fixed thickness and its vertical side surfaces 


$$
\begin{gathered}
P_{i}=\frac{h_{L i}+h_{P i}}{2} \times b_{i} \times \gamma_{i} \\
V_{s i}=V_{i} \times \sin \beta_{i} \\
V_{p i}=V_{i} \times \cos \beta_{i} \\
W_{i}=\left(y_{P i}-y_{L i}\right) \times \cos \beta_{i} \times \gamma_{w} \\
G_{i}=P_{i}+F_{i}=\frac{h_{L i}+h_{P i}}{2} \times b_{i} \times \gamma_{i}+F_{i} \\
G_{i}^{w}=G_{i}-b_{i} \times \frac{\left(a_{L i}+a_{P i}\right)}{2} \times \gamma_{w} \\
N_{i}=G_{i}^{w} \times \cos \beta_{i}-V_{s i}
\end{gathered}
$$

In these equations, the water pressure was included (the component $W_{i}$ ), water buoyancy pressure (the component $G_{i}^{w}$ ) and the load from external forces, such as buttresses, anchor plates or the ground loads (the vertical component $F_{i}$ and the horizontal component $V_{i}$ ).

Figure 9 shows the internal forces that occur in a single BFE and their elements: $Q_{i}-$ the force component $P_{i}$ perpendicular to the sliding surface; $V_{s i}$ - the force component $V_{i}$ perpendicular to the sliding surface; $R_{i}$ - the force component $P_{i}$ parallel to the sliding surface; $V_{p i}$ - the force component $V_{i}$ parallel to the sliding surface.

$$
\begin{gathered}
H_{i}=G_{i}^{w} \times \sin \beta_{i}+V_{p i}+W_{i} \\
T_{i}=N_{i} \times \operatorname{tg} \phi_{i}+c_{i} \times b_{i}
\end{gathered}
$$

On the basis of Equations [9] and [10], the complete holding force $\sum_{i=1}^{n} T_{i}$ and the complete sliding force $\sum_{i=1}^{n} H_{i}$ can be calculated as the sum of all forces BFE constituting the flat section, as well as the factor of safety $F S_{p}$ for each section, according to:

$$
F S_{p}=\frac{\sum_{i=1}^{n} T_{i}}{\sum_{i=1}^{n} H_{i}}
$$

Then, using the calculated values of $\sum_{i=1}^{n} H_{i}$ and $\sum_{i=1}^{n} T_{i}$ for all flat sections BFE of the analysed sliding body in the area of the relevant curves HED (HED I-VII in Fig. 7), the value of $H_{k}$ and $T_{k}$ for BED elements of the width $z_{k}$ (Fig. 10) limited by the flat sections can be calculated. It can be determined as the arithmetic mean from two neighbouring sections (Fig. 3), calculated according to:

$$
\begin{aligned}
& T_{k}=\frac{\left(\sum_{i=1}^{n} T_{i}\right)_{\text {left }}+\left(\sum_{i=1}^{m} T_{i}\right)_{\text {right }}}{2} \times z_{k} \\
& H_{k}=\frac{\left(\sum_{i=1}^{n} H_{i}\right)_{\text {left }}+\left(\sum_{i=1}^{m} H_{i}\right)_{\text {right }}}{2} \times z_{k}
\end{aligned}
$$

where: left - is with regard to the left section - the left wall of the BED (Fig. 10), right - is with regard to the right section - the right wall of the BED (Fig. 10).

After calculating $H_{k}$ and $T_{k}$ for all three-dimensional basic elements BED of the number $k$, the factor of safety of the whole sliding body in the area of the curve HED is calculated. For each, the factors of safety are obtained according to:

$$
F S_{b}=\frac{\sum_{k=1}^{k} T_{k}}{\sum_{k=1}^{k} H_{k}}
$$

The calculated amount $F S_{b}$ is determined by the three-dimensional factor of safety of the sliding body, limited by a relevant edge HED. When $F S_{b} \geq 1$ the block is stable, and when $F S_{b}<1$ it is not. As the density of the distribution of the assumed HED does not guarantee a precise demarcation of the line for which $F S_{b}=1$, the HED - fulfilling these conditions - is determined by the iteration of the coefficient dependence $F S_{b}$ on the distance HED from the scarp edge. In Figure 11, the result of the analysis is displayed for the section M-M, and for the others the result is produced analogically. As an example, for the assumed amount of the factor of safety $F S_{b}=1.0$ the obtained distance of the maximum range of the landslide hazard zone from Figure 11 is $Y \approx 56 \mathrm{~m}$. In the section $Y \approx 30-56 \mathrm{~m}$ the dimension has been determined for which the landslide hazard may be ex-

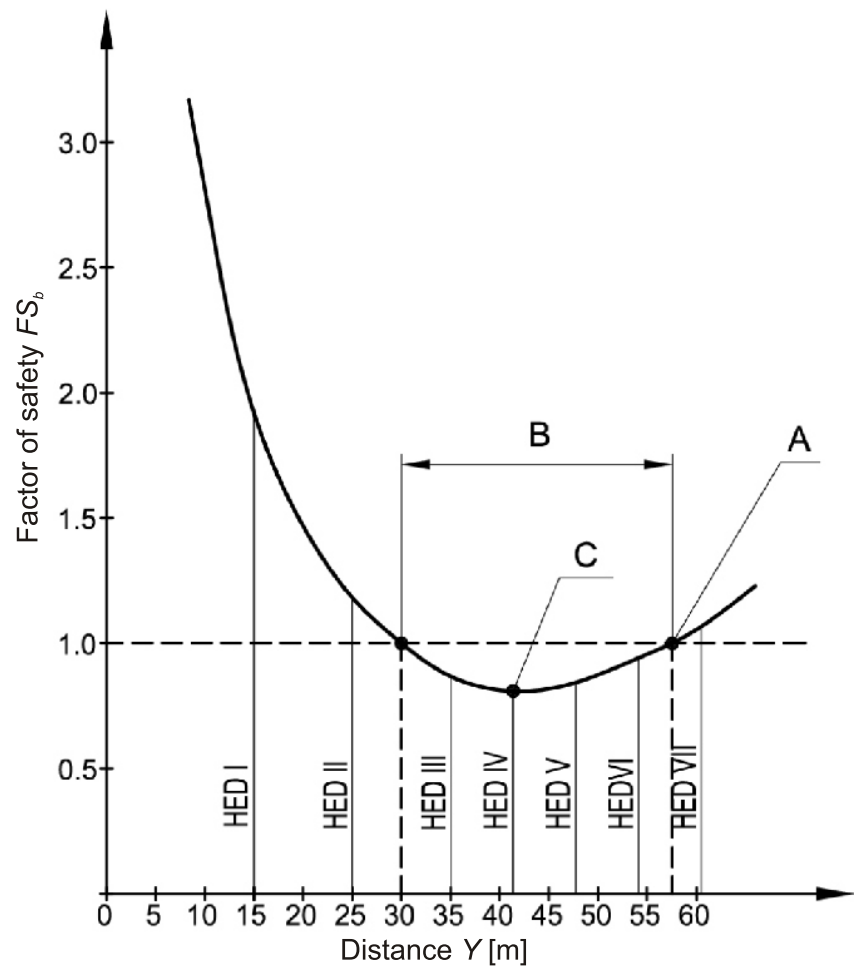

Fig. 11. The graph of dependencies of the safety factor $F S_{b}$ from the distance $Y$ between the line HED (the hypothetical outline of edges of landslide sliding body), and the base of the slope, the section M-M (from Fig. 7) as an example

A - range of a possible landslide of the furthest range; $\mathbf{B}$ - the scope of the dimension for which the landslide may occur; $\mathbf{C}$ - the range for which the stability of the soil wedge is the most doubtful; HED I-VII the range of hypothetical edges of the landslide sliding body 
A
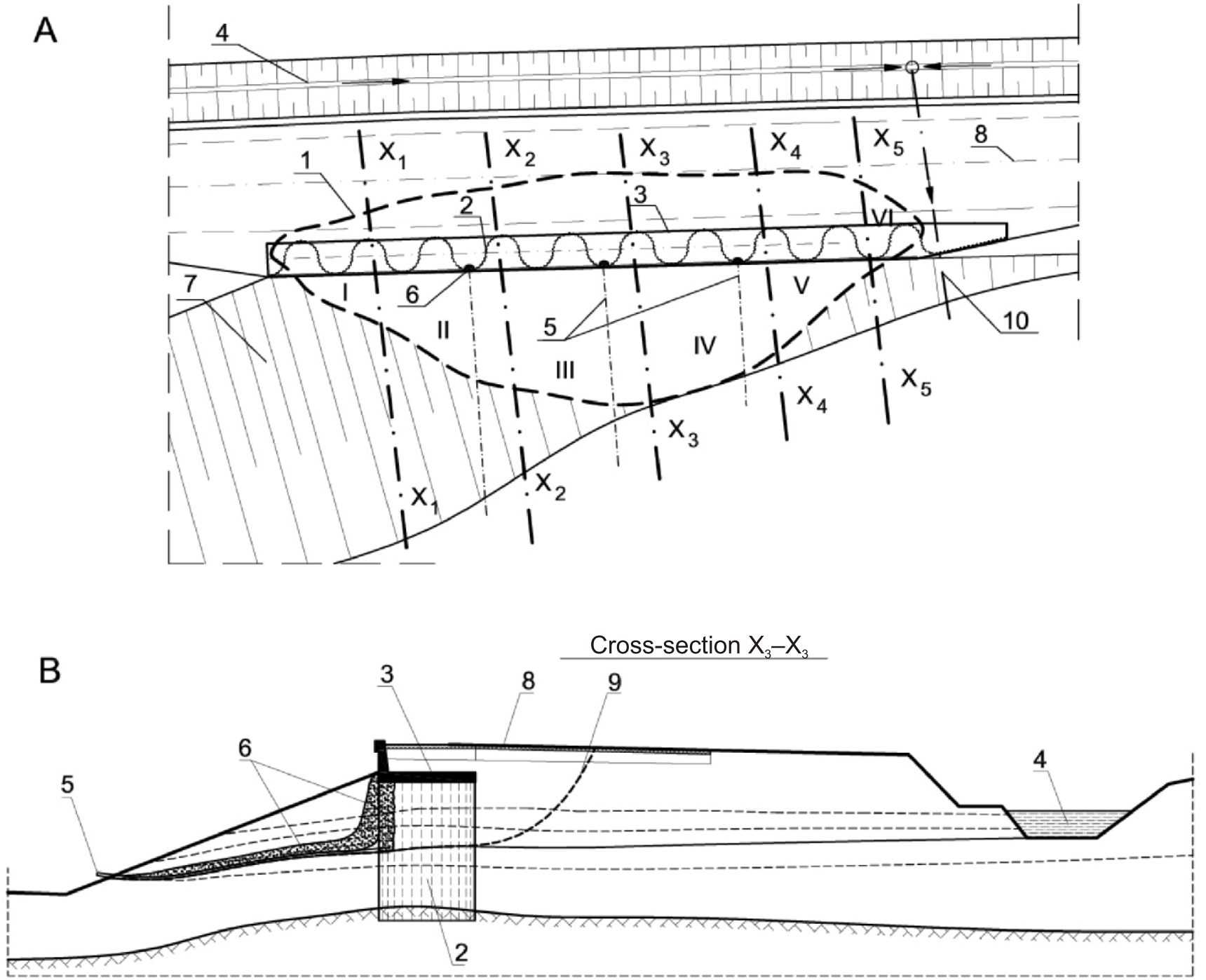

Fig. 12. The buttress from the tight wall of a wavy shape stopping the landslide

A - view from the top; $\mathbf{B}$ - the cross-section; 1 - landslide outline; 2 - tight wall; 3 - transfer slab; 4 - ditch with water; 5 - drain; 6 vertical filter; 7 - embankment; 8 - road; 9 - sliding surface; 10 - culvert

pected. The presented example makes it possible to determine the range of potential dimension developments of the landslide, which may endanger neighbouring objects, indicating one of the many possibilities of practical use of the STAB-3D method.

\section{OTHER EXEMPLARY STABILITY ANALYSIS WITH STAB-3D TO DESIGN BUTTRESSES TO STOP A LANDSLIDE}

In order to illustrate practical usage possibilities, the STAB-3D method for calculating the landslide stability of a gutter profile, an example of its practical use in determining the block stability of a structural landslide is presented (Fig. 12).

This landslide formed on the slope of a mountain and crosses a section of the main national road in the south Poland. From the slope side was a small area without outflow in which rainwater collected periodically. The embankment and construction of the road were sited on a layer of Holocene-aged soil (clay and silt), stratified sands, sensitive to changes in water content and easily becoming plasticised. This resulted in the launch of the landslide, moving with a large part of the road, which underwent slow landslide movements, lasting for a period of 50 years. This movement slowed down during periods without precipitation and accelerated during long-term rainfall. The part of the road surface subjected to landslide was systematically levelled using asphalt. Due to the location of a roadside inn in the vicinity of the landslide, it was necessary to widen the road and to add another lane for the whole length of the landslide. However, the most important thing was to inhibit the landslide's destructive action. Therefore, it was considered necessary to build buttresses, shown in Figures 12 and 13, which would stabilise the active landslide for many years.

The complexity of the stability analysis of the example from Figure 12 resulted from the lack of possibilities to protect the traffic from the sliding part of the road. The shape of the landslide block was known and was determined by measurements (Ukleja and Ukleja, 2001). The task involved leaving part of the landslide block under the road and determining its pressure level over a special buttress construction, connected to a tight 

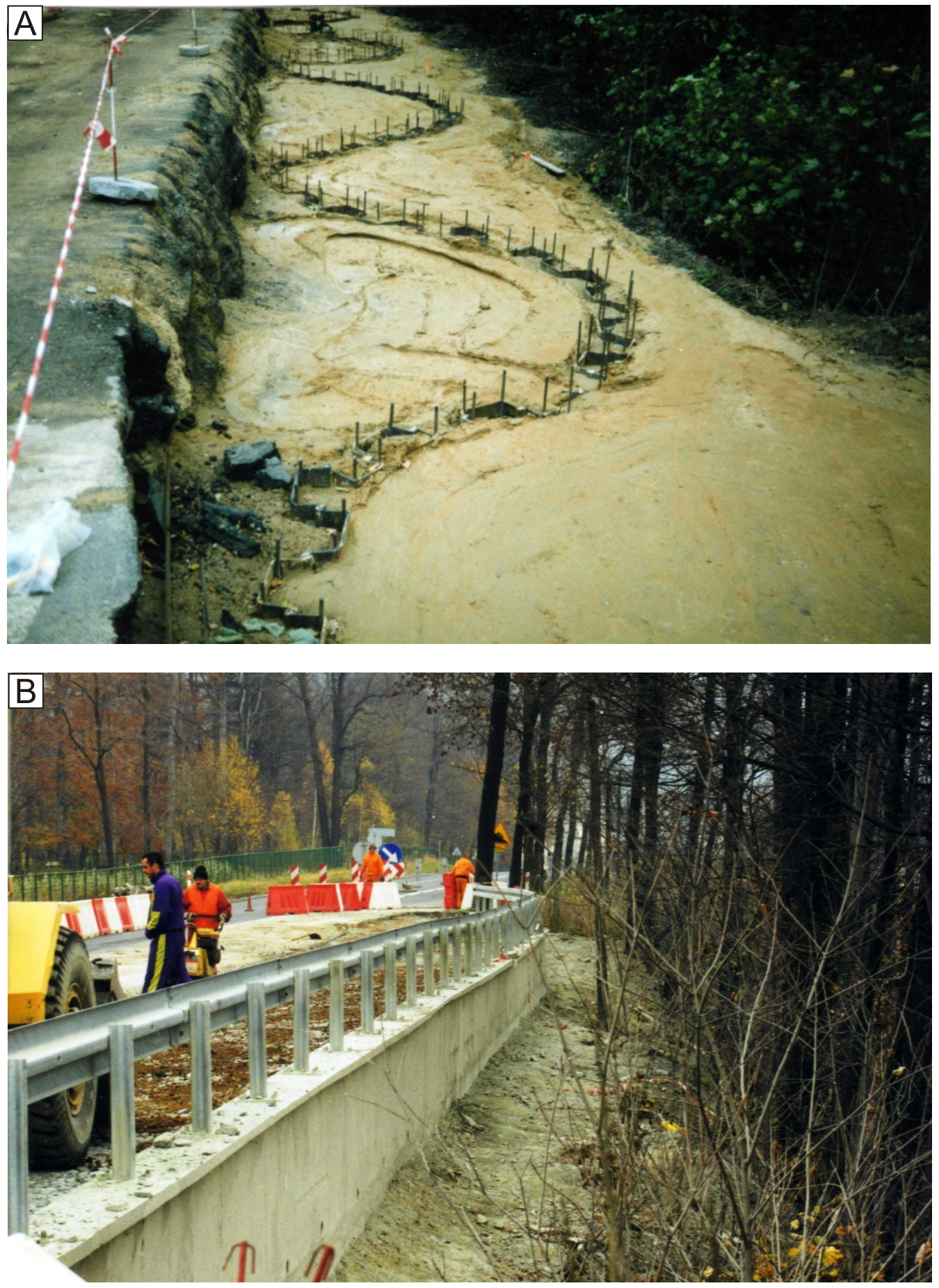

Fig. 13. Wavy buttress stabilising slope failure and widening the road from Figure 12

A - view of wavy tight wall from sheet piles; $\mathbf{B}$ - ready buttress after making slope support

steel wall. Its purpose was to stop an active landslide with the road and simultaneously to enable the broadening of the road in this place, by an additional two lanes. The initial synthetic data for the conducted static analysis and the results are shown in Figure 12; the tabulated results of the calculations are shown in Tables 1 and 2. According to the assumptions, the factor of safety of the landslide sliding body, the initial value of which is lower than $1.0(0.84)$, should reach 1.2 after the buttress installation. This factor of safety agrees with Polish standards for the general stability of retaining walls. Its value is 1.2 when the parameters of soil are multiplied by a reducing factor and the loads are multiplied by an increasing factor. It is equivalent to a factor of safety of 1.4 when the parameters of soil and loads are not multiplied. Many countries have their own rules and it is advisable to use the value of factor of safety of a particular country's standards.

In Tables 1 and 2 the following symbols are used: 
$\sum_{i=1}^{n} T_{i}-$ total force of friction for the whole section, being the sum of the components, from weight forces and external loads, perpendicular to the sliding surface, for $\mathrm{BFE}_{1}-\mathrm{BFE}_{\mathrm{n}}$;

$\sum_{i=1}^{n} H_{i}$ - total sliding force for the whole section, being the sum of the components, from weight forces and external loads, perpendicular to the sliding surface, for $\mathrm{BFE}_{1}-\mathrm{BFE}_{n}$;

$T_{k}$ - holding force for the $k$-th element BED $(k=I-V I I)$, calculated according to Equation [12];

$T^{\prime}{ }_{k}$ - reduced holding force for the assumed $F S_{b}^{\prime \prime \prime}=1.2$, $T_{k}=T_{k} \times F S_{b}^{\prime \prime \prime}$;

$H_{k}$ - sliding force for the $k$-th element BED $(k=I-V I I)$, calculated according to Equation [13];

$V_{k}$ - required force, which the buttress must accept, so that the factor of safety BED reaches the value of 1.2, $V_{k}=T_{k}^{\prime}-T_{k}$;

$w_{k}$ - as above, but on the length of $1 \mathrm{~m}$ of the supporting construction, $w_{k}=V_{k} / z_{k}$;

$F S_{b}^{\prime}$ - factor of safety BED which not takes into account the buttress, $F S_{b}^{\prime}=\frac{T_{k}}{H_{k}}$;
$F S_{b}^{\prime \prime}-$ reduced factor of safety BED, $F S_{b}^{\prime \prime}=\frac{F S_{b}^{\prime \prime \prime}}{F S_{b}^{\prime}}=\frac{1.2}{F S_{b}^{\prime}}$;

$F S_{b}^{\prime \prime \prime}$ - target, assumed factor of safety BED, which takes into account the buttress, $F S_{b}^{\prime \prime \prime}=\frac{T_{k}}{H_{k}}=12$.

Stability analysis was performed in two stages:

1. Knowing the geological structure, geotechnical parameters of the soil and the end result as the active landslide, the actual factor of safety was assumed to be less than or equal to 1.0 (as indicated by periodical temporary slope failure stopping effect). On this basis, technical verification of the calculations by calibration of the strength parameters (especially shear strength, which determines the value of the holding force $T_{k}$ ) of soil constituting the sliding layer was carried out to correspond to the parameters that allow for initiation of the slip. This was necessary because the soil parameters of the sliding layer change over time due to changes in water content, and the results of the laboratory tests of the soil lay-

Table 1

The results for block elements BED - not including influence of the buttress

\begin{tabular}{|c|c|c|c|c|c|c|c|c|}
\hline No. & $\begin{array}{c}\text { Element } \\
\text { BED }\end{array}$ & Section BFE & $\begin{array}{l}\sum_{i=1}^{n} T_{i} \\
{[\mathrm{kN}]}\end{array}$ & $\begin{array}{l}\sum_{\substack{i=1 \\
n}}^{n} H_{i} \\
{[\mathrm{kN}]}\end{array}$ & $\begin{array}{c}z_{k} \\
{[\mathrm{~m}]}\end{array}$ & $\begin{array}{c}T_{k} \\
{[\mathrm{kN}]}\end{array}$ & $\begin{array}{c}H_{k} \\
{[\mathrm{kN}]}\end{array}$ & $\begin{array}{c}\text { Factor of safety } \\
F S_{b}^{\prime} \\
\left(F S_{b}^{\prime}=\frac{T_{k}}{H_{k}}\right)\end{array}$ \\
\hline \multirow{2}{*}{1} & \multirow{2}{*}{ I } & $X_{0}-X_{0}$ & 0.0 & 0.0 & \multirow{2}{*}{6.0} & \multirow{2}{*}{460.8} & \multirow{2}{*}{568.8} & \multirow{2}{*}{0.81} \\
\hline & & $X_{1}-X_{1}$ & 153.6 & 189.6 & & & & \\
\hline \multirow{2}{*}{2} & \multirow{2}{*}{ II } & $X_{1}-X_{1}$ & 153.6 & 189.6 & \multirow{2}{*}{11.3} & \multirow{2}{*}{1794.4} & \multirow{2}{*}{2517.1} & \multirow{2}{*}{0.71} \\
\hline & & $X_{2}-X_{2}$ & 164.0 & 255.9 & & & & \\
\hline \multirow{2}{*}{3} & \multirow{2}{*}{ III } & $X_{2}-X_{2}$ & 164.0 & 255.9 & \multirow{2}{*}{11.3} & \multirow{2}{*}{2509.2} & \multirow{2}{*}{3203.0} & \multirow{2}{*}{0.78} \\
\hline & & $X_{3}-X_{3}$ & 280.1 & 311.0 & & & & \\
\hline \multirow{2}{*}{4} & \multirow{2}{*}{ IV } & $X_{3}-X_{3}$ & 280.1 & 311.0 & \multirow{2}{*}{11.5} & \multirow{2}{*}{3120.5} & \multirow{2}{*}{3322.4} & \multirow{2}{*}{0.94} \\
\hline & & $X_{4}-X_{4}$ & 262.6 & 266.8 & & & & \\
\hline \multirow{2}{*}{5} & \multirow{2}{*}{ V } & $X_{4}-X_{4}$ & 262.6 & 266.8 & \multirow{2}{*}{11.5} & \multirow{2}{*}{2270.1} & \multirow{2}{*}{2496.1} & \multirow{2}{*}{0.91} \\
\hline & & $X_{5}-X_{5}$ & 132.2 & 167.3 & & & & \\
\hline \multirow{2}{*}{6} & \multirow{2}{*}{ VI } & $X_{5}-X_{5}$ & 132.2 & 167.3 & \multirow{2}{*}{6.0} & \multirow{2}{*}{396.6} & \multirow{2}{*}{501.9} & \multirow{2}{*}{0.79} \\
\hline & & $X_{0}-X_{0}$ & 0.0 & 0.0 & & & & \\
\hline \multicolumn{5}{|c|}{$\begin{array}{l}\text { Factor of safety for the whole landslide sliding } \\
\text { body (LSB without support of buttress) } \\
\qquad F S_{b}=0.84\end{array}$} & $\Sigma$ & 10551.6 & 12609.2 & - \\
\hline
\end{tabular}

Table 2

The results of the block elements BED - including influence of the buttress

\begin{tabular}{|c|c|c|c|c|c|c|c|c|}
\hline No. & $\begin{array}{l}\text { Element } \\
\text { BED }\end{array}$ & $F S_{b}^{\prime}$ & $\begin{array}{c}F S_{b}^{\prime \prime} \\
\left(F B_{b}^{\prime \prime}=\frac{F S_{b}^{\prime \prime}}{F S_{b}^{\prime}}\right)\end{array}$ & $\begin{array}{c}T_{k} \\
{[\mathrm{kN}]}\end{array}$ & $\begin{array}{c}T_{k}^{\prime} \\
\left(T_{k}^{\prime}=T_{k} \times F S_{b}^{\prime \prime}\right) \\
{[\mathrm{kN}]}\end{array}$ & $\begin{array}{c}V_{k} \\
\left(V_{k}=T_{k}^{\prime}-T_{k}\right) \\
{[\mathrm{kN}]}\end{array}$ & $\begin{array}{c}w_{k} \\
{[k N / m]}\end{array}$ & $\begin{array}{c}\text { Factor of safety } \\
F S_{b}^{\prime \prime \prime} \\
\left(F S_{b}^{\prime \prime \prime}=\frac{T_{k}^{\prime}}{H_{k}}\right)\end{array}$ \\
\hline 1 & $\mathrm{I}$ & 0.81 & 1.48 & 460.8 & 682.6 & 221.8 & 37.0 & 1.20 \\
\hline 2 & II & 0.71 & 1.68 & 1794.4 & 3020.5 & 1226.1 & 108.5 & 1.20 \\
\hline 3 & III & 0.78 & 1.53 & 2509.2 & 3843.6 & 1334.4 & 118.1 & 1.20 \\
\hline 4 & IV & 0.94 & 1.28 & 3120.5 & 3986.8 & 866.3 & 75.3 & 1.20 \\
\hline 5 & V & 0.91 & 1.32 & 2270.1 & 2995.3 & 725.2 & 63.1 & 1.20 \\
\hline 6 & VI & 0.79 & 1.52 & 396.6 & 602.3 & 205.7 & 34.3 & 1.20 \\
\hline \multicolumn{4}{|c|}{$\begin{array}{l}\text { Factor of safety of the whole supported } \\
\text { landslide body } \\
\qquad F S_{b}^{\prime}=1.20\end{array}$} & $\Sigma$ & 15131.0 & 4579.4 & - & - \\
\hline
\end{tabular}


ers are not wholly representative of the conditions of the moving landslide.

2. Assuming the same parameters as above and the required standard a factor of safety of $F S_{b} \geq 1.2$, the necessary bearing capacity of the buttresses, varied in each of its sections between cross sections (Fig. 12A), was defined. Each of the sections of the proposed buttresses was given the task of taking over a specific amount of sliding force, expressed as and (Table 2).

The sizes of forces $V_{k}$ and $w_{k}$ obtained as a result of the analysis made it possible to design the buttress in such a way as to achieve the assumed factor of safety for all landslides of $F S_{b}^{\prime}=1.2$, using the STAB-3D method. The results of the landslide stability calculations made it possible to design various buttresses tailored to the needs of durability, ensuring the stability of the landslide.

\section{CONCLUSIONS}

In some cases the LEM approach, which has been hitherto applied, accounts for the most reliable and durable effects (particularly in the case of long-lasting active slope failures) due to the underlying assumptions that correspond to reality. Therefore, this approach is more effective than the numerical model based on the theory of continuum mechanics. It is therefore recommended to search for models that adopt the LEM 2D model for the purpose of a 3D approach. This article presents the approach named STAB-3D, which is different to others, since it combines a well-known and simple analysis of flat section divided into $2 \mathrm{D}$ vertical stripes and the $3 \mathrm{D}$ analysis of the whole sliding body of landslide. Such a sliding body was divided into smaller elements found between flat sections (parallel to the surface slide direction). This approach allows all the forces that balance out in a sliding body to be disregarded (proven correct by Hungr, 1987) and to determine sliding and bearing forces as well as the factor of safety for the whole sliding body of the landslide. This brings about a radical simplification of the procedure with no practical adverse impact upon correctness and accuracy.

This method has the following features and benefits:

- based on uncomplicated calculations in conducting the analysis, it allows the main forces influencing the sliding body of the landslide to be balanced;

- it makes it possible to define the slope stability or the safety factor for landslides activated earlier, after the implementation of support structures or stability support;

- the algorithm allows the shape of the potential landslide to be separated thanks to the assumption of the potential edges of the sliding surfaces, based on which the most disadvantageous shape is determined.

However, the method is used only when dealing with the stratification of layers determining the privileged sliding surfaces at their contact, and when the sliding direction is clearly defined. However, this limitation alone does not decrease the usefulness of the method due to the ubiquity of such cases, for example in flysch or at the place of contact between rocky layers and silty or clayey ground.

Based on the assumptions and the algorithm of the STAB-3D method, a number of analyses were conducted; two examples were presented. As a result of analysing the ensuing landslide, it has been possible to define the safety factor of the of landslide sliding body. Moreover it has been possible to determine the forces necessary to strengthen the soil body mass and to define the safety factor with regard to the influence of the designed buttress from sheet piles.

Acknowledgements. The author is grateful to Prof. A. Isakov, Dr. S. Burlon and the anonymous Reviewer as well as Prof. T.M. Peryt for the revision and valuable comments which significantly improved the manuscript.

\section{REFERENCES}

Chen, R.H., Chemeau, J.L., 1983. Three-dimensional limit equilibrium analysis of slopes. Geotechnique, 33: 31-40.

Cheng, Y.M., Liu, H.T., Au, S.K., 2005. Location of critical three-dimensional non-spherical failure surface with applications to highway slopes. Computers and Geotechnics, 32: 387-399.

Cheng, Y.M., Yip, C J., 2007. Three-dimensional asymmetrical slope stability analysis extension of Bishop's, Janbu's, and Morgenstern-Price's techniques. Journal of Geotechnical and Geoenvironmental Engineering, 133: 1544-1555.

Cytowicz, N.A., 1958. Mechanika gruntów (in Polish): 217-219. Wyd. Geol., Warszawa.

Griffiths, D.V., Marquez, R.M., 2007. Three-dimensional slope stability analysis by elasto-plastic finite elements. Géotechnique, 57: 537-546.

Hicks, M.A., Spencer, W.A., 2010. Influence of heterogeneity on the reliability and failure of a long 3D slope. Computers and Geotechnics, 37: 948-955.

Huang, C.C., Tsai, C.C., 2000. New method for 3D and asymmetrical slope stability analysis. Journal of Geotechnical and Geoenvironmental Engineering, 26: 917-927.

Huang, C.C.,Tsai, C.C., Chen, Y.H., 2002. Generalized method for three-dimensional slope stability analysis. Journal of Geotechnical and Geoenvironmental Engineering, ASCE 128: 836-848.
Hungr, O., 1987. An extension of Bishop's simplified method of slope stability analysis to three dimensions. Geotechnique, $\mathbf{3 7}$ : 113-117.

Hungr, O., Salgado, F. M., Byrne, P. M. 1989. Evaluation of a three-dimensional method of slope stability analysis. Canadian Geotechnical Journal, 26: 679-686.

Hutchinson, J.N., Sarma, S.K., 1985. Discussion on three-dimensional limit equilibrium analysis of slopes. Geotechnique 35 : 215.

Kalatehjari, R., Arefnia, A., A Rashid, A.S, Ali, N., Hajihassani, M., 2015. Determination of three-dimensional shape of failure in soil slopes. Canadian Geotechnical Journal, 10: 1283-1301.

Li, A.J., Merifield, R.S., Lyamin, A.V., 2010. Three-dimensional stability charts for slopes based on limit analysis methods. Canadian Geotechnical Journal, 47: 1316-1334.

Loehr, J.E., Mc Coy, B.F., Wright, S.G., 2004. Quasi-three-dimensional slope stability analysis method for general sliding bodies. Journal of Geotechnical and Geoenvironmental Engineering, 130: $551-560$.

McCombie, P.F., 2009. Displacement based multiple wedge slope stability analysis. Computers and Geotechnics, 36: 332-341.

Michalowski, R.L., 1989. Three-dimensional analysis of locally loaded slopes. Geotechnique, 39: 27-38. 
Michalowski, R.L., 2010. Limit analysis and stability charts for 3D slope failures. Journal of Geotechnical and Geoenvironmental Engineering, 136: 583-593.

Nian, T.K., Huang, R.Q., Wan, S.S., Chen, G.Q., 2012. Three-dimensional strength-reduction finite element analysis of slopes: geometric effects. Canadian Geotechnical Journal, 49 574-588.

Shen, H., Klapperich, H., Abbas, S.M., Ibrahim, A., 2012. Slope stability analysis based on the integration of GIS and numerical simulation. Automation in Construction, 26: 46-53.

Ukleja, J., 1996. Calculation of range of slides of structural type on haulage benches in surface mines (in Polish with English summary). Górnictwo Odkrywkowe, 38: 56-70.

Ukleja, K., Ukleja, J., 1999. The stabilization of road body formed on landslips. Górnictwo Odkrywkowe, 41: 149-157.

Ukleja, K., Ukleja, J., 2001. Structural landslide supporting by construction of a steel assisting buttress. XXIV Z.S.M.G. Lądek Zdrój, P.N.I.G.iH. Wrocław University of Technology, Conferences, 73: 525-526.

Ukleja, K., Ukleja, J., Tatarczyk, B., 1999. Stabilisation of a road body shaped in a slope failure. XIIth European Conference on Soil Mechanics and Geotechnical Engineering, Geotechnical Engineering for Transportation Infrastructure, Amsterdam, The Netherlands 7-10 June, 2: 1391-1397.

Vandamme, J., Zou, Q., Ellis, E., 2012. Novel particle method for modeling the episodic collapse of soft coastal bluffs. Geomorphology, 138: 295-305.
Vandamme, J., Zou, Q., 2013. Investigation of slope instability induced by seepage and erosion by a particle method. Computers and Geotechnics, 48: 9-20.

Wei, W.B., Cheng, Y.M., Li, L., 2009. Three-dimensional slope failure analysis by the strength reduction and limit equilibrium methods. Computers and Geotechnics, 36: 70-80.

Wilun Z., 1982. Zarys geotechniki (in Polish): 305-307. Wydawnictwo Komunikacji i Łączności, Warszawa.

Xie, M., Esaki, T., Cai, M., 2006. GIS-based implementation of three-dimensional limit equilibrium approach of slope stability. Journal of Geotechnical and Geoenvironmental Engineering, 132: 656-660.

Zamani, M., 2008. A more general model for the analysis of the rock slope stability. Sadhana, 33: 433-441.

Zhang, J., Li, Z., Qi, T., 2005. Mechanism analysis of landslide of a layered slope induced by drawdown of water level. Science in China, Series E: Technological Sciences, 48: 136-145.

Zhang, X., 1988. Three-dimensional stability analysis of concave slopes in plan view. Journal of Geotechnical Engineering, 114: 658-671.

Zhang, Y., Chen, G., Wang, B., Li, L., 2013. An analytical method to evaluate the effect of a turning corner on 3D slope stability. Computers and Geotechnics, 53: 40-45.

Zhu, D.Y, 2001. A method for locating critical slip surfaces in slope stability analysis. Canadian Geotechnical Journal, 38: 328-337. 